\title{
Editorial HIV AND TUBERULOSIS
}

\author{
Col VC OHRI, MD*
}

MJAFI 1995; 51 : 229-230

KEY WORDS : HIV; Tuherculosis; Diagnosis.

$\mathbf{E}$ ven in a developed country like USA, where till $1985,6 \%$ annual decline in tuberculosis was achieved over preceding 30 years, a reversed trend of increase by $3-6 \%$ has occurred $[1,2]$. HIV infection is cited as one of the major causes. Naturally, scenario for tuberculosis is far more grim in places like sub-Saharan Africa which are in grip of HIV infection and where tuberculosis has been endemic [3]. Southeast Asia, especially India, is vying for top honours for HIV infection and will soon face a similar dual problem of the same magnitude. We are grateful to Jayaswal et al [4] for serving a timely warning in this issue.

CD4 and macrophage dysfunction in HIV infected patients places them at a high risk for both primary and reactivation tuberculosis [1]. Within 3 years of the description of AIDS in 1981 [5], increased incidence of tuberculosis in AIDS afflicted was reported [6]. Role of endemicity of tuberculosis contributing to increased incidence in AIDS patients was demonstrated by comparing Haitian and non-Haitian populations.

Nosocomial acquisition of primary tuberculosis with accelerated progression in HIV infected has been demonstrated by molecular biology techniques like restriction fragment length polymorphism of DNA of isolates of Mycobacterium tuberculosis [7].

Because $M$. tuberculosis is more virulent than other HIV associated pathogens like Pneumocystis carinii and $M$. avium intracellulare complex, it is more likely to cause disease at earlier stage of immune deficiency without pre-existing AIDS [1]. In fact, a study in Zaire has demonstrated that pulmonary tuberculosis could not be used as a marker for staging of HIV infection, the incidence being more or less equal over the entire spectrum of CD4 counts [8].

For obvious reasons, tuberculosis disseminates far more frequently from its primary location in lungs in HIV infected than in HIV negative cases. Much higher incidence of extrapulmonary tuberculosis (EPTB) has been recorded in HIV infected [6]. Blood culture is positive for $M$. tuberculosis in $26-42 \%$. Other preferred sites are lymph nodes $(67-90 \%$ AFB positive) and CNS (abscess, tuberculoma). AFB positivity in faeces in $40 \%$ of HIV infected is not regarded as a manifestation of EPTB because sputum is inevitably positive for AFB in these cases [1].

Chest radiograms are suggestive of tuberculosis in $85 \%$ of HIV patients with pulmonary tuberculosis. Hilar lymphadenopathy is seen in $42 \%$, pleural effusion in $29 \%$, predominantly upper lobe involvement $25 \%$, miliary pattern $13 \%$ and cavitation in only $6 \%$. In advanced AIDS, regular picture of pulmonary tuberculosis gives way to hilar adenopathy, pleural effusion and miliary pattern [1].

Tuberculin skin sensitivity test more than $10 \mathrm{~mm}$ induration is seen in $71 \%$ of $\mathrm{HIV}$ infected 2 years before onset of AIDS and deoreases to $33 \%$ after development of AIDS signifying development of anergy. Hence

*Professor and Head, Dept of Microbiology, Armed Forces Medical College, Pune 411040. 
negative tuberculin test does not exclude diagnosis of tuberculosis in HIV infected [1]. Probably it is this anergy which accounts for less incidence of cavitation in pulmonary tuberculosis and explains decrease in sputum AFB positivity from $82 \%$ to $31 \%$ with progression of severity of AIDS [1]. A study in Zambia has shown the necessity of using culture methods and also newer techniques in diagnosis of pulmonary tuberculosis [9].

Response to treatment with usual antitubercular regime is almost as good as in HIV negative cases, treatment failure rate being $2-3 \%$. Extension of treatment by 6 months can bring down relapse rates from $9 \%$ to $2 \%$ [10].

A US study in 1989-90 has shown increase of incidence of tuberculosis in HIV infected to $5.1 \%$ and incidence of HIV in tuberculosis patients to $39 \%$ [11]. It is expected that tuberculosis treatment may account for $50 \%$ HIV related costs [12]. Developing nations will not be able to bear this heavy burden on their national exchequer and poor AIDS patient will not be able to afford this. Result, inevitably will be, development and emergence of multiple drug resistance in $M$. tuberculosis (MDRT). This MDRT is more difficult to treat and has a more rapid progression to fatality with median of 4-16 weeks from diagnosis to death [2].

MDRT is already a problem to reckon with. By 1992, 6 outbreaks of MDRT in hospitals and AIDS facilities are on record, involving 5-65 patients in each outbreak. Not only have these outbreaks affected HIV positive inmates of hospitals and AIDS farilities but also involved health care workers, guards and family members [13].

In India, it is essential to take stock of HIV and tuberculosis at all levels. It is essential that HIV antibody testing should be carried out regularly in tuberculosis patient and HIV infected should be put through battery of investigations for diagnosis of tuberculosis at regular intervals. When diagnosed, comprehensive and extended anti-tubercular treatment should be accomplished. Development of nosocomial tuberculosis in HIV infected, especially MDRT, has put a question mark on creation of HIV/AIDS wards or hospitals.

\section{REFERENCES}

1. Barness PF, Block AB, Davidson PT, Snider DE. Tuberculosis in patients with human immunodeficiency virus infection. N Engl J Med 1991; 324 : 1644-50.

2. Snider DE, Roper WL. The new tuberculosis. N Engl J Med 1992; 326 : 703-5.

3. DeCock KM, Soro B, Couibaly IM, Lucas SB. Tuberculosis and HIV infection in sub-Saharan Africa JAMA 1992; 268 : 1581-7.

4. Jayaswal R, Arora PN, Panda BN. HIV in tuberculosis. Medical Journal Armed Forces India 1995; 51 : 259-63.

5. Gottlieb MS, Schrott R, Schranker HM, et al. Pneumocystis pneumonia and mucosal candidiasis in previously healthy homosexual men :evidence of a new cellular immunodeficiency. N Engl J Med 1981; 305 : 1425-31.

6. Pitchenik AE, Cole C, Russell BW, Fischl M, Spira T], Snider DE. Tuberculosis, atypical mycobacteria and the acquired immunodeticiency syndrome among Haitian and non-Haitian population in South Florida. Ann Intern Med 1984: 101 : 641-5.

7. Daley CL, Small PM, Schecter GF, et al. An outbreak of tuberculosis with accelerated progression amiongst persons infected with immunodeficiency virus. An analysis using restriction fragment polymorphism. N Engl J Med 1992; 326 : 231-5.

8. Mukedi Y, Perriens JH, St Louis M, ef al. Spectrum of immunodeficiency in HIV-1 infected patients with pulmonary tuberculosis in Zaire. Lancet 1993; 342 : 143-6.

9. Elliot AM, Narnaamba K, Allen BW, et al. Negative sputum smear results in HIV positive patients with pulmonary tuberculosis in Lusaka, Zambia. Tubercle and Lung Disease 1993; $74: 191-4$.

10. Perriens JH, St Louis ME, Mukadi YB, et al. Pulmonary tuberculosis in HIV infected patients in Zaire. A controlled trial of treatment of either 6 or 12 months. N Engl J Med 1995; $332:$ 779-84.

11. Rosenblum LS, Castro KG, Dooley S, Morgan M. Effect of HIV infection and tuberculosis on hospitalisation and cost of care for young adults in the United States, 1985 to 1990 . Ann Intern Med 1994; 121 : 786-92.

12. Foster S, Buve A, Mukonka V, O'Connel A. Costs of treating HIV related illness at a district hospital in Zambia. VIII International conference on AIDS, Amsterdam, July 1992. Abstract No POD 5769.

13. Dooley SW, Jarvis WR, Marton WV, Snider DE. Multidrug resistant tuberculosis. Ann Intern Med 1992; $117: 257-9$. 